\title{
Resistance to Fas-mediated apoptosis is restored by cycloheximide through the downregulation of cellular FLIP $\mathrm{L}$ in NK/T-cell lymphoma
}

\author{
Yoon Kyung Jeon ${ }^{1,2}$, Heejung Kim², Soo Oh Park ${ }^{2}$, Hye Young Choi ${ }^{2}$, Young A Kim ${ }^{3}$, \\ Sung-Shin Park ${ }^{3}$, Ji Eun Kim ${ }^{3}$, Yong Nyun Kim ${ }^{2}$ and Chul-Woo Kim ${ }^{1,2}$ \\ ${ }^{1}$ Department of Pathology, Seoul National University College of Medicine, Seoul, Korea; ${ }^{2}$ Tumor Immunity \\ Medical Research Center, Cancer Research Institute, Seoul National University College of Medicine, Seoul, \\ Korea and ${ }^{3}$ Department of Pathology, Seoul City Boramae Hospital, Seoul, Korea
}

\begin{abstract}
Extranodal NK/T-cell lymphoma (NKTL), nasal type, is a highly aggressive neoplasm and is strongly associated with Epstein-Barr virus (EBV). In this study, we demonstrate that EBV-positive NKTL cell lines, namely, Hank-1, NK-YS, and NK-L, are resistant to Fas-mediated apoptosis induced by anti-Fas antibodies despite high levels of Fas surface expression and no mutation in the Fas gene. Fas stimulation of Hank-1 and NK-YS cells showed little processing of caspase 8 , caspase 3 , or bid, although the proximal signaling molecules of the deathinducing signaling complex, namely, Fas, Fas-associated protein with a death domain, caspase 8, and bid were present in these cells. Consistent with previous reports on the hypermethylation of death associated protein (DAP) kinase in NKTLs, the promoter of DAP kinase was methylated and its mRNA not detected in Hank-1 cells. However, the restoration of DAP kinase expression by 5-aza-2'-deoxycytidine did not sensitize Hank-1 to Fasmediated apoptosis, indicating that DAP kinase deficiency does not contribute to resistance to Fas-mediated apoptosis. Since etoposide-induced apoptosis involved caspase 3 activation in Hank-1 and NK-YS cells, the caspase 3-dependent apoptotic machinery appears to be intact. Interestingly, cotreatment of Hank-1 with cycloheximide, a protein synthesis inhibitor, markedly sensitized cells to Fas-mediated apoptosis along with caspase 8 activation and C-FLIP $P_{L}$ (cellular FLICE inhibitory protein long form) downregulation. Moreover, immunohistochemistry on paraffin-embedded tissue revealed c-FLIP expression in $39 \%$ (14 of 36 ) of NKTL patients. Taken together, these findings indicate that $\mathrm{C}-\mathrm{FLIP}_{\mathrm{L}}$-mediated resistance to Fas contributes to the development and progression of NKTLs. This study also suggests that agents capable of downregulating c-FLIP $\mathrm{L}$ could be used to treat NKTL.

Laboratory Investigation (2005) 85, 874-884. doi:10.1038/labinvest.3700291; Published online 16 May 2005
\end{abstract}

Keywords: apoptosis; cycloheximide; DAP kinase; EBV; Fas; FLIP; NK/T-cell lymphoma

Fas (CD95/Apo-1), a member of the tumor necrosis factor (TNF) receptor superfamily, is a well-known member of the death receptor pathway. Fas stimulation by Fas ligand or an agonistic antibody leads to Fas oligomerization and the recruitment of FADD (Fas-associated protein with a death domain) and

Correspondence: Dr C-W Kim, MD, Department of Pathology, Seoul National University College of Medicine, 28 Yongon-dong, Chongno-gu, Seoul 110-799, Korea.

E-mail: cwkim@plaza.snu.ac.kr

Presented at the 94th Annual Meeting of the United States and Canadian Academy of Pathology, San Antonio, TX, February 26 March 4, 2005.

Received 15 November 2004; revised 22 March 2005; accepted 25 March 2005; published online 16 May 2005 caspase 8/FLICE (FADD-like IL-1 $\beta$-converting enzyme) to the intracellular death domains of Fas, which results in the formation of the death-inducing signaling complex (DISC). DISC formation then triggers the sequential activations of caspase 8 and caspase 3, either directly or through a mitochondrial pathway. ${ }^{1,2}$ Fas-mediated apoptosis plays an important role in immune system surveillance as evidenced by its ability to induce tumor cell death, and thus is regarded as a tumor suppressor mechanism. ${ }^{3}$ However, many tumors escape the immune system by developing diverse ways to bypass normal Fas activation. One example is provided by somatic mutation of the Fas gene, which has been demonstrated in various lymphoid and nonlymphoid malignancies, including NK/T-cell lymphoma 
(NKTL). ${ }^{4,5}$ Mutations of the cytoplasmic death domain of Fas might block effective DISC formation, ${ }^{6}$ and defects in its transmembrane domain can result in the secretion of soluble Fas, which acts as a decoy receptor for Fas ligand. ${ }^{7}$ Ineffective DISC formation, despite of intact Fas signaling molecules, could also endow Fas resistance to lymphoblastoid cells. ${ }^{8}$ Apoptosis can also be evaded via the overexpression of inhibitory signaling molecules involved in Fas-mediated cell death, and these include cellular FLICE-inhibitory protein (c-FLIP). c-FLIP contains a 'death effector domain' and binds to FADD and caspase 8 in DISC, thereby blocking caspase 8 activation and the resultant apoptotic cascade.$^{9,10}$ Abnormally high c-FLIP expression has been reported in many malignancies, and it has also been reported that the downregulation of c-FLIP sensitizes variable tumor cells to Fas-mediated apoptosis. ${ }^{11-14}$

NKTL is a neoplasm that originates from natural killer (NK) cells and rarely from cytotoxic T cells. Epstein-Barr virus (EBV) is latently infected in nearly all NKTLs irrespective of ethnic or geographic origin, and thus EBV is believed to be an important pathogenic component. Although some patients respond to chemotherapy and radiotherapy, many are resistant to conventional chemotherapy and succumbed to this disease. ${ }^{15,16}$ Latent EBV infections are classified into three types according to the genes expressed, and NKTL is committed to type 2 latency expressing Epstein-Barr virus nuclear antigen 1 (EBNA1) and latent membrane protein 1 (LMP1). LMP1 functions as a constitutively activated TNF receptor, and is essential for the transformation and immortalization of EBV-infected cells. ${ }^{17,18}$ Moreover, LMP1 is known to exhibit extensive oncogenic properties associated with its activation of the NF- $\kappa \mathrm{B}$ and mitogen-activated protein kinase (MAPK) pathways. ${ }^{19,20}$ Recently, it has been reported that LMP1 also activates the PI3K/ Akt pathway to promote cell survival in several cell lines. $^{21,22}$ The biologic aggressiveness of NKTL is due to the low cell death rates of NKTL cells and/or their high rates of proliferation. This low cell death rate may be the result of several possible defects in apoptosis, whereas the high proliferation rate may be due to various cell-cycle regulation abnormalities. Some of these changes arise from the involvement of specific proteins such as LMP1, or defects in signaling pathways. Interestingly, tumors with defects in death receptor pathways often exhibit resistance to chemotherapy and radiotherapy. Therefore, the elucidation of these abnormal apoptotic pathways provides information helpful for the development of new and more efficacious treatment modalities.

In this study, we demonstrate that NKTL cell lines are resistant to Fas-mediated apoptosis mainly due to defects in proximal signaling, and that this occurs despite the expression of intact molecules involved in Fas-mediated apoptosis. Death associated protein
(DAP) kinase methylation, although present, was not found to be substantially involved in the Fas resistance of Hank-1. However, cycloheximide (CHX), a protein synthesis inhibitor, restored Fas sensitivity in Hank-1, an NKTL cell line with high LMP1 expression, by suppressing C-FLIP $_{\mathrm{L}}$. The inhibition of Fas-mediated apoptosis probably through c-FLIP is presumed to be an important mechanism in the development and progression of NKTL.

\section{Materials and methods}

\section{Cell Lines and Reagents}

Three NKTL cell lines, namely, Hank-1, NK-YS, and NK-L were maintained in a $5 \% \mathrm{CO}_{2}$ atmosphere at $37^{\circ} \mathrm{C}$. Hank-1 and NK-YS are two IL-2-dependent cell lines that were established from nasal-type NKTLs latently infected with EBV. ${ }^{23,24}$ Hank-1 cells were kindly provided by Dr Kagami and Dr Seto (Aichi Cancer Center, Nagoya, Japan) and cultured in COS medium (Cosmo Bio, Tokyo, Japan) containing $5 \%$ human plasma and $100 \mathrm{U} / \mathrm{ml}$ of human recombinant IL-2 (Chiron-France, Suresnes, France). NK-YS cells were kindly provided by Dr Tsuchiyama and Dr Yoshino (Okayama University Medical School, Okayama, Japan) and maintained in Iscove's modified Dulbecco's medium (IMDM; Gibco, Grand Island, NY, USA) containing 10\% FBS (Gibco, Gaithersburg, MD, USA), 1\% kanamycin and $100 \mathrm{U} / \mathrm{ml}$ of IL-2. NK-L cells were kindly provided by Dr Seto (Aichi Cancer Center, Nagoya, Japan) and cultured in RPMI 1640 medium containing 10\% FBS, $50 \mathrm{U} / \mathrm{ml}$ penicillin, $50 \mathrm{mg} / \mathrm{ml}$ streptomycin, $2 \mathrm{mM}$ L-glutamine, and $200 \mathrm{U} / \mathrm{ml}$ of IL-2. The human T-cell lymphoma cell line, Jurkat, and the EBVinfected lymphoblastoid cell line, SKW6.4 were purchased from American Type Culture Collection (ATCC, Manassas, VA, USA), and cultured in RPMI 1640 medium containing $10 \%$ FBS, $50 \mathrm{U} / \mathrm{ml}$ penicillin, $50 \mathrm{mg} / \mathrm{ml}$ streptomycin, and $2 \mathrm{mM}$ L-glutamine. Mouse anti-human Fas monoclonal antibody (IgM clone 7C11; Coulter-Immunotech, Marseilles, France) was used up to $200 \mathrm{ng} / 5 \times 10^{5} / \mathrm{ml}$ to induce Fas-mediated apoptosis in the different cell lines. Etoposide, CHX (Sigma, St Louis, MO, USA), dexamethasone, actinomycin $\mathrm{D}$, and staurosporin (BioVision, Mountain View, CA, USA) were added directly to the culture media at different concentrations.

\section{Cell Proliferation and Viability Assay}

Hank-1, NK-YS, NK-L, Jurkat, and SKW6.4 cells were seeded at a density of $1-4 \times 10^{4} /$ well in 96 -well tissue culture plates. The cells were treated with anti-Fas monoclonal antibody (7C11) or with other apoptotic inducers for 8-24 hours (h), and then incubated with MTS [3-(4,5-dimethylthiazol-2-yl)- 
5(3-carboxymethoxyphenyl)-2-(4-sulfophenyl)-2Htetrazolium] (Promega, Madison, WI, USA) at $37^{\circ} \mathrm{C}$ for an additional hour. Sample spectrophotometric absorbance at $490 \mathrm{~nm}$ was determined using an Ultra Multifunctional Microplate Reader. Each experiment was performed in triplicate and results were averaged.

\section{Flow Cytometry}

To determine apoptosis, treated cells were harvested and incubated for $10 \mathrm{~min}$ at room temperature (RT) with $3 \mu \mathrm{l}$ of fluorescein isothiocyanate (FITC)-conjugated annexin V reagent (Pharmingen, San Diego, CA, USA) and $1 \mu \mathrm{l}$ of $50 \mu \mathrm{g} / \mathrm{ml}$ propidium iodide (PI) in binding buffer. Cells were analyzed using a FACScan (Epics XL, Coulter, Marseille, France). Annexin V positive and PI positive cells were both deemed apoptotic. Data are presented as means \pm standard deviation (s.d.), and the significances of differences were determined using the Mann-Whitney $U$-test in SPSS 11.0.1 (Stanford version).

To evaluate Fas cell surface expression, about $2 \times 10^{5}$ cells were washed twice with cold PBS containing $0.1 \% \mathrm{BSA}$, and incubated for $30 \mathrm{~min}$ on ice with $10 \mu \mathrm{g} / \mathrm{ml}$ FITC-conjugated anti-CD95 monoclonal antibody (BD Pharmingen, San Diego, CA, USA). After washing twice and fixing with $4 \%$ paraformaldehyde, 5000 cells were analyzed by flow cytometry.

To measure mitochondrial membrane potential $\left(\Delta \Psi_{\mathrm{m}}\right)$ disruption, $1 \times 10^{5}$ treated cells were incubated with $20 \mathrm{nM}$ 3,3'-diethyloxacarbocyanine iodide $\left(\mathrm{DiOC}_{6}\right)$ (Molecular Probes, Eugene, OR, USA) for $20 \mathrm{~min}$ at $37^{\circ} \mathrm{C} . \Delta \Psi_{\mathrm{m}}$ was determined by flow cytometric analysis.

\section{Sequencing of Fas and Caspase 3 Gene Transcripts}

Total RNA was isolated using TRI reagent (Molecular Research Center, Cincinnati, OH, USA), and $2 \mu \mathrm{g}$ of total RNA was used for cDNA synthesis with oligo(dT) primers and M-MLV reverse transcriptase (Promega, M531A). Fas transcripts were amplified using two pairs of primers designed to amplify the entire coding region. The sequences of the primers used were as follows: F1 5'-TCTTTCACTTCGGAG GATTGCT-3' ${ }^{\prime}$ R1 $5^{\prime}$-GAACTTTCTGTTCTGCTGTGT CTTG-3', F2 5'-TGCCAAGAAGGGAAGGAGTA-3', R2 5'-ACCAAGCAGTATTTACAGCCAG-3', which were designed from Fas mRNA (GeneBank accession no. M67454). PCR was performed using a $5 \mathrm{~min}$ initial denaturation at $95^{\circ} \mathrm{C}, 31$ amplification cycles (denaturation for $1 \mathrm{~min}$ at $95^{\circ} \mathrm{C}$, annealing for $1 \mathrm{~min}$ at $53^{\circ} \mathrm{C}$, and extension for $1 \mathrm{~min}$ at $72^{\circ} \mathrm{C}$ ) and a 10 min final extension at $72^{\circ} \mathrm{C}$. Amplified PCR products were purified using a PCR purification kit (Qiagen GmbH, Hilden, Germany) and directly sequenced from both directions using an ABI PRISM
377 Sequencer (Applied Biosystems, Foster City, CA, USA).

\section{Methylation-Specific PCR and RT-PCR for DAP Kinase}

To demethylate CpG islands, Hank-1 cells were incubated with $1-10 \mu \mathrm{M}$ of 5 -aza-2'-deoxycytidine (5-aza) for 6 days with media changes on day 2 and 4. For methylation-specific PCR (MSP), DNA was modified with $1 \mu \mathrm{g}$ of genomic DNA using a CpGenome $^{\text {TM }}$ DNA modification kit (Chemicon, Temecula, CA, USA) according to the manufacturer's protocol. The PCR primers used for the unmethylated reaction were: forward 5'-GGAGGA TAGTTGGATTGAGTTAATGTT- ${ }^{\prime}$ and reverse $5^{\prime}$ CAAATCCCTCCCAAACACCAA- $3^{\prime}$. And, the primers used for the methylated reaction were: forward $5^{\prime}$-GGATAGTCGGATCGAGTTAACGTC- $3^{\prime}$ and reverse $5^{\prime}$-CCCTCCCAAACGCCG A-3'. The PCR conditions used were same for both PCRs and are as follows: $5 \mathrm{~min}$ of initial denaturation at $95^{\circ} \mathrm{C}, 40$ amplification cycles (denaturation for $1 \mathrm{~min}$ at $95^{\circ} \mathrm{C}$, annealing for $1 \mathrm{~min}$ at $58^{\circ} \mathrm{C}$, and extension for $1 \mathrm{~min}$ at $72^{\circ} \mathrm{C}$ ), and $10 \mathrm{~min}$ final extension at $72^{\circ} \mathrm{C}$.

For the RT-PCR of DAP kinase, total RNA extraction and cDNA synthesis were carried out as described above. cDNA was amplified using the following primers, forward 5'-GATAGAAATGTCCC CAAACCTCG- $3^{\prime}$ and reverse $5^{\prime}$-TCTTCTTTGGATCC TTGACCAGAA- $3^{\prime}$. The PCR conditions used were $5 \mathrm{~min}$ at $95^{\circ} \mathrm{C}, 28$ amplification cycles $\left(1 \mathrm{~min}\right.$ at $95^{\circ} \mathrm{C}$, $1 \mathrm{~min}$ at $60^{\circ} \mathrm{C}$, and $1 \mathrm{~min}$ at $72^{\circ} \mathrm{C}$ ), and $10 \mathrm{~min}$ at $72^{\circ} \mathrm{C}$. Human $\beta$-actin cDNA was used as a control for RT-PCR, and amplified using the primers described above.

\section{Western Blot}

After washing, cells were lysed with $2 \times$ sample buffer $(20 \mathrm{mM}$ TRIS, pH 8.0, $2 \mathrm{mM}$ EDTA, $2 \mathrm{mM}$ DTT, $1 \mathrm{mM} \mathrm{Na}_{3} \mathrm{VO}_{4}, 2 \%$ SDS, and $20 \%$ glycerol). Protein concentrations were determined using a BCA protein assay kit (Pierce, Rockford, IL, USA). In all, $30-50 \mu \mathrm{g}$ of total cellular proteins were subjected to $8-15 \%$ SDS-PAGE and transferred to PVDF (polyvinylidene fluoride) membranes. The membranes were then blocked with $5 \%$ nonfat dry milk in TTBS $(0.1 \%$ Tween 20 in Tris-buffered saline) for $1 \mathrm{~h}$ at RT or overnight at $4^{\circ} \mathrm{C}$. Membranes were then incubated overnight at $4^{\circ} \mathrm{C}$ with anticaspase 3 (1:500, rabbit polyclonal, Santa Cruz, CA, USA), anti-cleaved caspase 3 (1:500, rabbit polyclonal, Cell Signaling, Beverly, MA, USA), anticaspase 8 (1:100, rabbit polyclonal, Santa Cruz), anti-caspase 9 (1:500, rabbit polyclonal, Santa Cruz), anti-bcl-2 (1:500, mouse polyclonal, Santa Cruz), anti-bcl-xL (1:500, rabbit polyclonal, Santa Cruz), anti-bax (1:500, mouse polyclonal, Santa Cruz), antihuman Fas (APO-1) antibody (1:500, mouse polyclonal, clone APO-1-3, Alexis Corporation, Coger, 
Paris, France), anti-human FADD (1:250, mouse, BD Pharmingen, San Diego, CA, USA), anti-FLIP (1:250, rabbit polyclonal, Upstate Biotechnology, NY, USA), anti-LMP1 (1:250, mouse, BD Pharmingen), and anti-DAP kinase (1:500, mouse monoclonal, BD Transduction). After washing with TTBS 3 times, membranes were then incubated with a secondary horseradish peroxidase-conjugated antibody at 1:5000 for $1 \mathrm{~h}$ at RT. Blots were visualized using an enhanced chemiluminescence (ECL) detection kit (Amersham, Buckinghamshire, England).

\section{Caspase 3 Enzyme Activity Assay}

Cells were harvested by centrifugation at $450 \mathrm{~g}$ for $10 \mathrm{~min}$ at $4^{\circ} \mathrm{C}$. After removing supernatant, cell pellets were resuspended in $100 \mu \mathrm{l}$ of cell lysis buffer $(50 \mathrm{mM}$ HEPES pH 7.5, $1 \mathrm{mM}$ DTT, $0.1 \mathrm{mM}$ EDTA, $0.1 \%$ CHAPS), and lysed by repetitive freezing in $-70^{\circ} \mathrm{C}$ and thawing on ice. The cell lysates were cleared by centrifugation at $15000 \mathrm{~g}$ for $20 \mathrm{~min}$ at $4^{\circ} \mathrm{C}$ and the resulting supernatants were defined as cell extract. In all, $100 \mu \mathrm{g}$ of cell extracts was, respectively, added to caspase assay buffer (100 mM HEPES pH 7.5, 10\% sucrose, 0.1\% CHAPS, $10 \mathrm{mM}$ DTT, $200 \mu \mathrm{M}$ DEVD-pNA) with or without $100 \mu \mathrm{M}$ Boc-D. These mixtures were then incubated at $37^{\circ} \mathrm{C}$ for $4 \mathrm{~h}$ and the absorbance due to pNA (a yellowish color) release was measured using an ELISA reader at $405 \mathrm{~nm}$.

\section{Immunohistochemistry}

To detect the expression of c-FLIP in tumor tissues, 39 NKTL patients were randomly selected and immunohistochemical staining was performed using anti-c-FLIP mouse monoclonal antibody (Santa Cruz). After deparaffinization and rehydration, slides were immersed in $1 \mathrm{mM}$ ethylene diamine tetraacetic acid (EDTA) buffer, and boiled in a steamer for $1 \mathrm{~h}$. After blocking endogenous peroxidase activity, primary antibody was applied at a dilution of $1: 50$ overnight at $4^{\circ} \mathrm{C}$. The slides were then incubated in biotinylated goat anti-mouse/ rabbit Ig (LSAB Kit, DAKO, Carpinteria, CA, USA) and then in a solution of streptavidin-biotin complex (LSAB Kit, DAKO). Immunoreactivity was visualized using 3,3-diaminobenzidine. A tissue microarray slide containing 50 cases of Hodgkin lymphoma was immunostained at the same time as a positive control for c-FLIP expression. ${ }^{14}$

\section{Results}

Resistance to Fas-Mediated Apoptosis in NKTL Cell Lines

To determine the initial sensitivity of NKTL cell lines to Fas-mediated apoptosis, Hank-1, NK-YS, and NK-L cell lines were treated with anti-human
Fas mAb (IgM clone 7C11). As a positive control for Fas-mediated apoptosis, Jurkat or the SKW6.4 cells were included in all experiments. Apoptotic cell percentage was defined as the sum of annexin Vand/or PI-positive cells. In addition, cell viability and proliferate activity were assessed by MTS assay. Hank-1 cells exhibited apoptosis only in $7.3 \pm 5.7 \%$ (mean \pm s.d.) of cells after treatment with anti-Fas $\mathrm{mAb}$ for $8 \mathrm{~h}$ and in $17.6 \pm 9.8 \%$ after treatment for $24 \mathrm{~h}$ as compared with SKW6.4 cells, which showed $50.3 \pm 9.8 \%$ at $8 \mathrm{~h}$ and $64.0 \pm 11.6 \%$ at $24 \mathrm{~h}$, respectively. The significances of the differences in Fasmediated apoptosis shown by SKW6.4 and Hank-1 cells were estimated using the Mann-Whitney $U$-test $(P<0.01)$. Other NKTL cell lines, namely, NK-YS and NK-L, also exhibited strong resistance to Fas-mediated apoptosis (Figure 1a). Consistent with the results of the apoptosis assay, MTS assays revealed only about $23 \%$ growth inhibition in Hank-1 in contrast to marked inhibition (up to $66 \%$ of the control level) in Jurkat cells after $24 \mathrm{~h}$ of treatment with anti-Fas mAb. Strikingly, NK-YS and NK-L cells showed little impairment of cell viability or proliferation by Fas stimulation (Figure 1b).

During apoptosis, alterations in mitochondrial membrane potential $\left(\Psi_{\mathrm{m}}\right)$ are followed by cytochrome $c$ release and caspase activation., ${ }^{1,2}$ Thus, we examined $\Psi_{\mathrm{m}}$ changes by measuring the uptake of the mitochondrial specific dye DiOC $_{6}$ in cells undergoing apoptosis. As shown in Figure 1c, a distinct loss of $\Psi_{\mathrm{m}}$ was observed in SKW6.4 cells after $8 \mathrm{~h}$ of anti-Fas mAb treatment, but not in Hank1 or NK-YS cells, which correlated well with Fasmediated apoptosis resistance results. These data indicated that Hank-1 and NK-YS cells are resistant to Fas-mediated cell death.

\section{Normal Fas Expression and the Presence of Proximal Fas-Signaling Molecules in NKTL Cell Lines}

To exclude the possibility that impaired Fas expression causes resistance to Fas-mediated apoptosis in NKTL cell lines, we evaluated Fas cell surface expression by flow cytometry and total Fas protein levels by Western blot analysis. More than $80 \%$ of Hank-1, NK-YS, NK-L, and control Jurkat cells showed Fas cell surface expression (Figure 2a), and similar levels of Fas protein were observed in SKW6.4, Hank-1, and NK-YS cells (Figure 2b). Next, we confirmed the presence of only a single gene transcript of Fas in Hank-1, NK-YS, and Jurkat cell lines by repetitive RT-PCR analyses using two pairs of primers described in Materials and methods (data not shown). Sequencing of the purified RT-PCR products (in duplicate) using the above primers revealed no mutations or deletions of Fas gene transcripts (data not shown). As seen in Figure 2b, Western blot analysis of Hank-1 and NK-YS cells using anti-Fas antibody revealed Fas of expected size (48 kDa) and similar as the control SKW6.4 
cells. Next, we examined the presence of other Fas signaling molecules, such as FADD, procaspase 8 , and c-FLIP by Western blot. Immunoblotting data disclosed the presence of these molecules in Hank1, NK-YS, and control Jurkat cells (Figure 2c). These
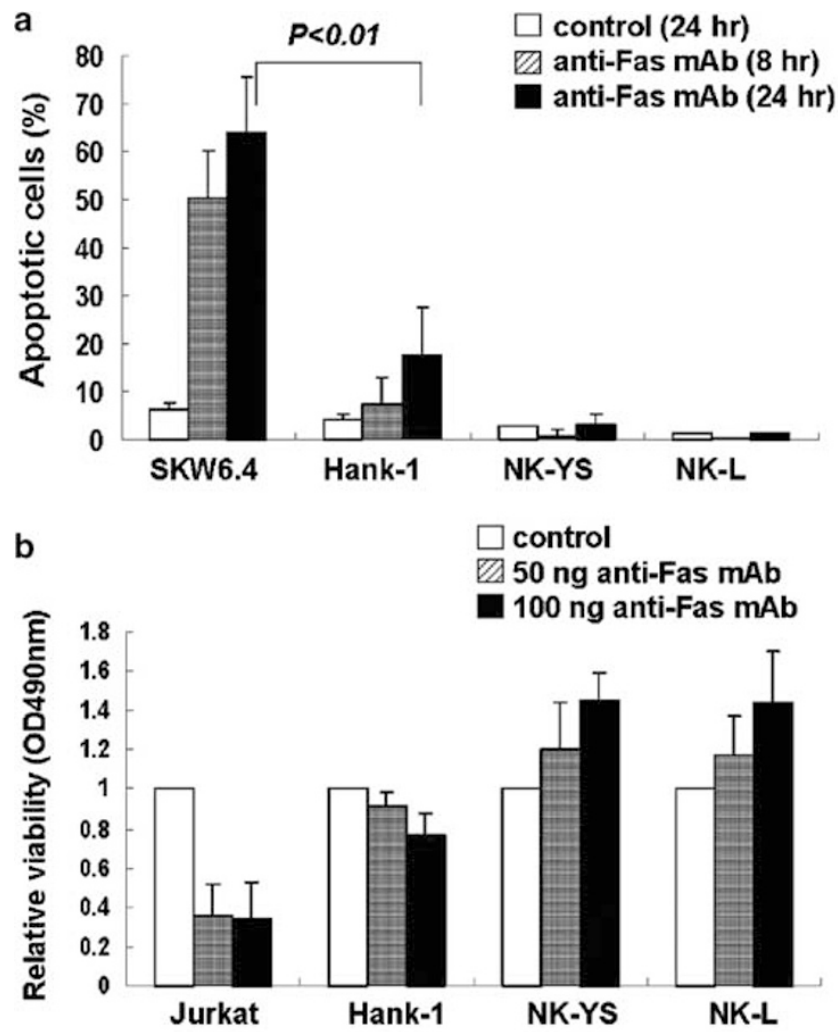

C

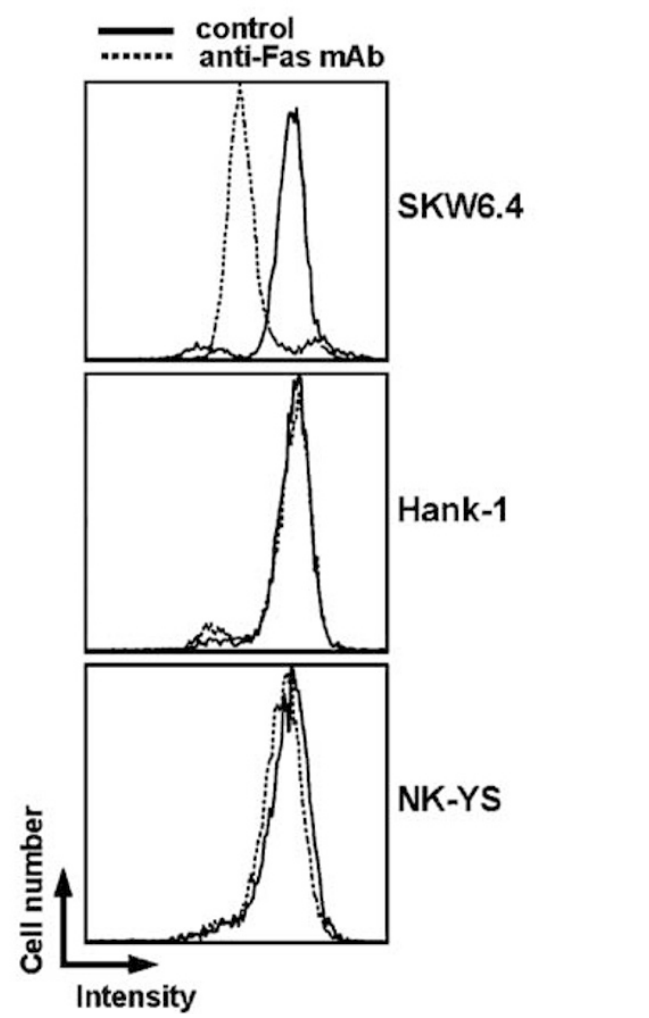

data indicated that normal Fas is expressed on the cell surface and that Fas-associated signaling molecules are present in Hank-1 and NK-YS cells.

a
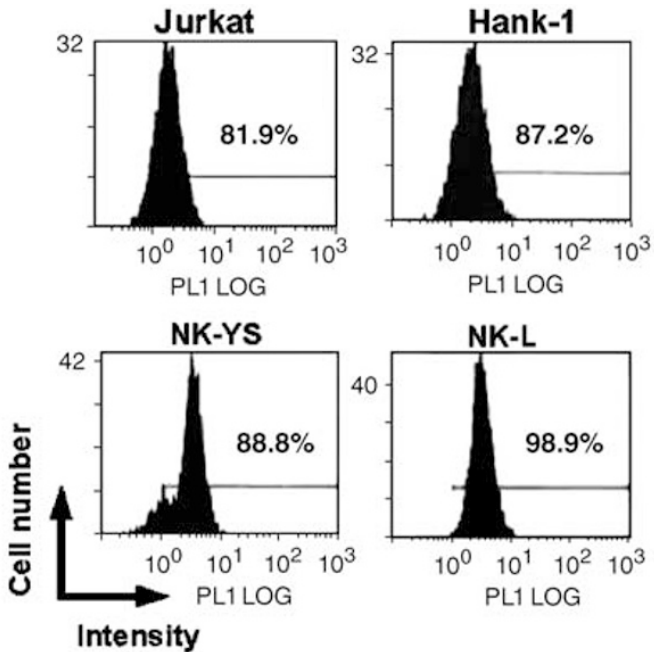

b

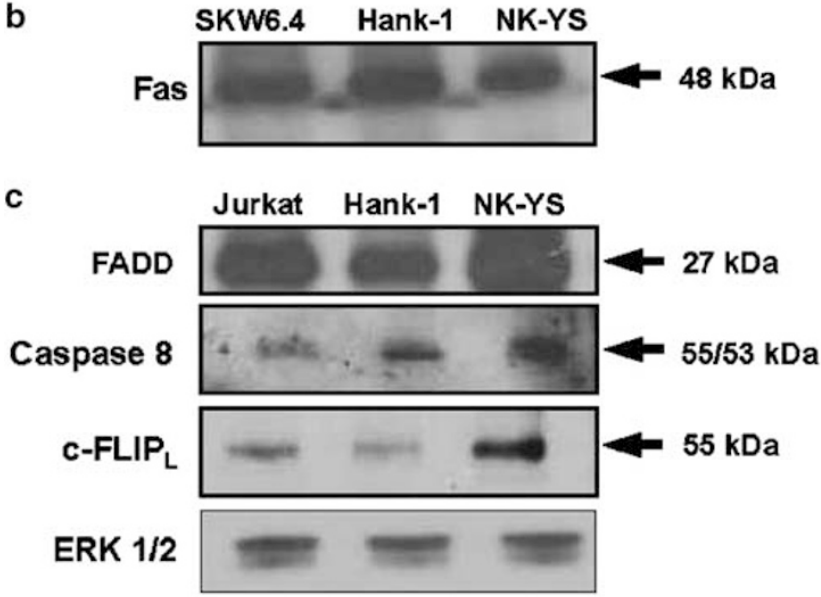

Figure 2 Intact Fas signaling molecules in NKTL cell lines. (a) To evaluate cell surface Fas expression, control Jurkat cells and NKTL cell lines, namely, Hank-1, NK-YS, and NK-L $\left(2 \times 10^{5}\right.$ cells $)$ were stained with FITC-conjugated anti-CD95 (Fas) monoclonal antibody and analyzed by flow cytometry. (b) In all, $30 \mu \mathrm{g}$ of total cell lysates from each cell line were separated by SDS-PAGE and subjected to Western blot analysis using anti-Fas antibody. (c) In all, 30-50 $\mu$ g of cell lysates from each cell line were separated by SDS-PAGE and subjected to western blot analysis using antiFADD, anti-caspase 8, and anti-c-FLIP.

Figure 1 Resistance to Fas-mediated apoptosis in NKTL cell lines. (a) Cells were treated with anti-Fas mAb (7C11) $200 \mathrm{ng} /$ $5 \times 10^{5} \mathrm{cells} / \mathrm{ml}$ for 8 or $24 \mathrm{~h}$, stained with annexin V-propidium iodide (PI), and analyzed by flow cytometry. The percentage of apoptotic cells shown is based on the total numbers of annexin Vor PI-positive cells. Data represent means of five separate experiments, and error bars represent standard deviations (s.d.). (b) Cells were treated with anti-Fas $\mathrm{mAb} 50 \mathrm{ng} / 5 \times 10^{5} \mathrm{cells} / \mathrm{ml}$ or $100 \mathrm{ng} / 5 \times 10^{5} \mathrm{cells} / \mathrm{ml}$ for $24 \mathrm{~h}$, and subjected to MTS assay to evaluate cell viability and proliferation. Data are the average absorbances at $490 \mathrm{~nm}$ of two experiments performed in triplicate. (c) To determine mitochondrial membrane potential $\left(\Psi_{\mathrm{m}}\right)$ disruption, $1 \times 10^{5}$ cells, were treated for $8 \mathrm{~h}$ with anti-Fas $\mathrm{mAb}$, incubated with $20 \mathrm{nM} \mathrm{3,3}$-diethyloxacarbocyanine iodide $\left(\mathrm{DiOC}_{6}\right)$ and analyzed by flow cytometry. 


\section{Dispensability of DAP Kinase in Fas-Mediated Apoptosis in Hank-1 Cells}

DAP kinase, a proapoptotic serine/threonine kinase with a death domain, is involved in the execution of apoptosis mediated by Fas, TNF- $\alpha$, and interferon- $\gamma$ in some cells. ${ }^{25}$ The downregulation of DAP kinase by its promoter methylation has been suggested associated with Fas resistance, as was found in Tand NK/T-cell lymphoma as well as B-cell lymphoma. ${ }^{26}$ Therefore, we evaluated the methylation status of DAP kinase gene and its possible involvement in Fas-mediated apoptosis in Hank-1 cells. DAP kinase was methylated and its mRNA expression was undetected in Hank-1 cells. Although a methylated band of DAP kinase ( $98 \mathrm{bp}$ ) was reduced by 5-aza treatment in Hank-1 cells, and its mRNA (343 bp) and protein expression 160 (160 kDa) appeared vs $\beta$-actin (Figure 3a), the recovery of DAP kinase expression per se did not sensitize Hank-1 cells to Fas-mediated apoptosis (Figure 3b). These data suggest that DAP kinase is dispensable in the Fas-mediated apoptosis of Hank-1 cells.

\section{Reduced Activations of Caspase 3, Caspase 8, and bid After Anti-Fas mAb Treatment in NKTL Cell Lines}

The transduction and execution of apoptotic signals requires the coordinated action of caspases, which are present in cells as inactive procaspases and activated by the removal of a prodomain and cleavage into large and small subunits. ${ }^{27}$ Caspase 3 is the final common pathway in the execution of both the death-receptor and the mitochondrial apoptotic pathways. ${ }^{2,27}$ To explore the downstream effects of Fas stimulation, caspase 3 activation was evaluated by Western blot using two different anti-caspase 3 antibodies. The first antibody recognized inactive procaspase $3(32 \mathrm{kDa})$, intermediate (22 kDa), and active (19 and $17 \mathrm{kDa}$ ) forms of caspase 3 , whereas the second antibody (anti-cleaved caspase 3-specific antibody) recognized selectively the intermediate and active forms of caspase 3 . In SKW6.4 and Jurkat cells, caspase 3 was converted from its inactive form to its active forms, as evidenced by a marked reduction in the level of the inactive proform (solid arrow) and an increase in the active forms (dash arrows), after only $2 \mathrm{~h}$ of antiFas mAb treatment (Figure 4a). In contrast, Hank-1 cells showed little detectable active caspase 3 after $8 \mathrm{~h}$ of treatment with anti-Fas mAb (Figure 4a). In NK-YS cells, procaspase 3 did not quantitatively change and the active forms of caspase 3 did not appear even after $24 \mathrm{~h}$ of Fas stimulation. The pattern of active forms of caspase 3 noted in immunoblots using anti-cleaved caspase 3-specific antibody was in accordance with the above results (Figure 4a). In addition, caspase 3 enzyme activity was increased by 11-fold in control SKW6.4 cells, only by 1.8-fold in Hank-1 cells, and by little in NK-

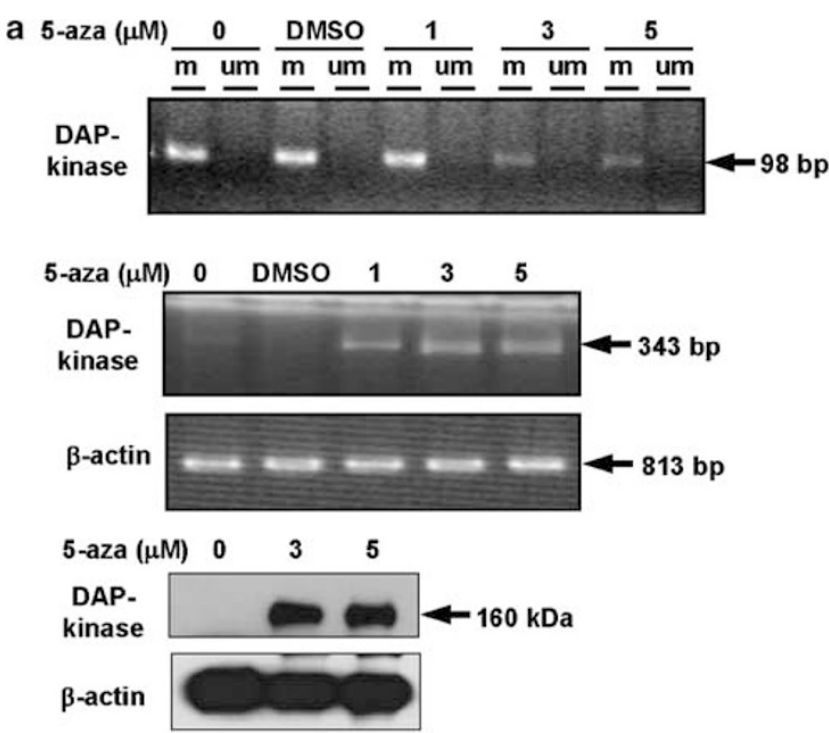

b

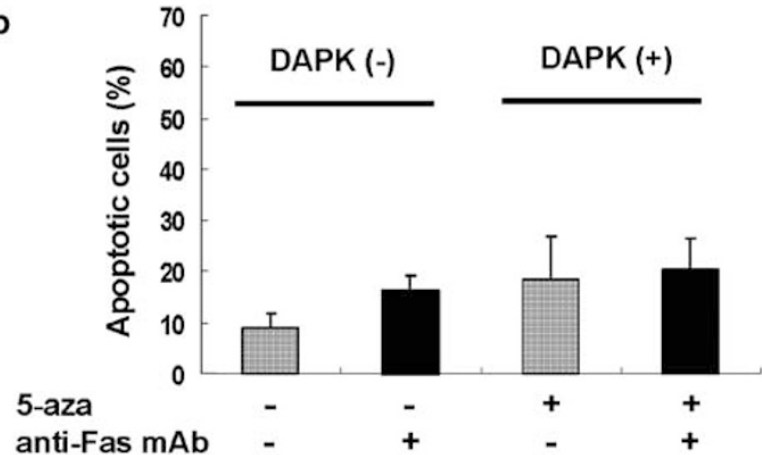

Figure 3 DAP kinase methylation and its effect on Fas-mediated apoptosis in Hank-1 cells. (a) Hank-1 cells were incubated with 5aza at 1,3 , and $5 \mu \mathrm{M}$ for 6 days, and total DNA and RNA were extracted. Then, methylation-specific PCR (MSP) was performed to detect methylated and unmethylated bands (upper panel). To evaluate demethylation of DAP kinase and its expression, RT-PCR for DAP kinase was also performed using the primers detailed in Materials and methods (middle panel). In all, $30 \mu \mathrm{g}$ of total cell lysate from each cell line was separated by SDS-PAGE and subjected to Western blot analysis using anti-DAP kinase antibody (lower panel). (b) Hank-1 cells were pretreated with or without 5 -aza at $5 \mu \mathrm{M}$ for 6 days and then stimulated with anti-Fas $\mathrm{mAb}$ $200 \mathrm{ng} / 5 \times 10^{5} \mathrm{cells} / \mathrm{ml}$ for $24 \mathrm{~h}$. Fas-mediated apoptosis was evaluated by annexin V-PI staining and flow cytometric analysis.

YS cells (Figure 4b), which was consistent with Western blot results.

To exclude the possibility of functional defects in caspase 3-mediated apoptosis per se in Hank-1 and NK-YS, we examined the cell death induced by etoposide, a prototypic reagent for caspase 3-dependent apoptosis. Hank-1 and NK-YS cells treated with etoposide displayed apoptosis accompanied by caspase 3 activation (Figure 5a,b). These results indicate that the caspase 3 -dependent apoptotic machinery, but not the Fas-mediated machinery, is intact in these NKTL cell lines. Next, we examined the proximal Fas-signaling pathways before caspase 3 activation, as represented by 
880

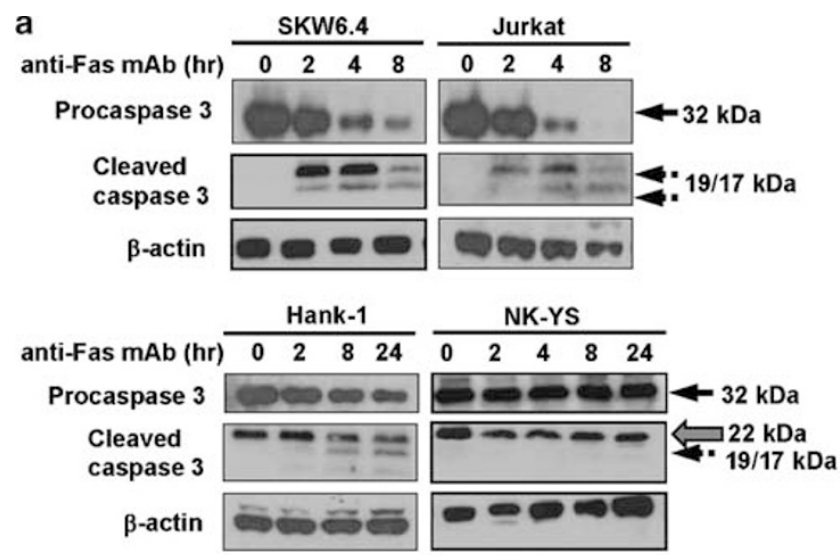

b

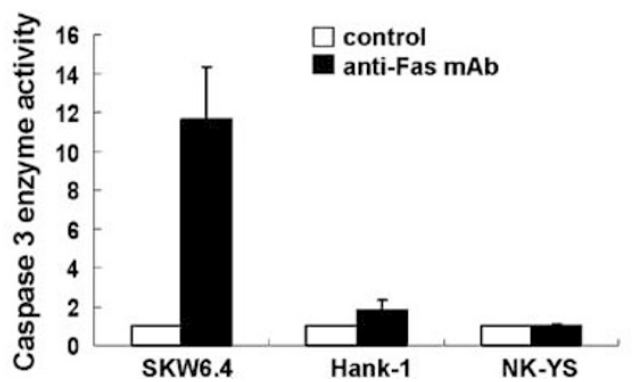

Figure 4 Effect of anti-Fas $m A b$ on caspase 3 activation in Hank-1 and NK-YS cells. (a) Cells were treated with $200 \mathrm{ng} / 5 \times 10^{5}$ cells/ $\mathrm{ml}$ of anti-Fas mAb for the described hours, and $30 \mu \mathrm{g}$ of total cellular proteins were subjected to SDS-PAGE. Caspase 3 activation was analyzed by Western blotting using two different antibodies that recognized procaspase $3(32 \mathrm{kDa}$, solid arrow) and active cleaved caspase 3 (19 and $17 \mathrm{kDa}$, dash arrows), respectively. In Hank-1 and NK-YS cells, intermediate caspase $3(22 \mathrm{kDa}$, gray arrows) were found to be constitutively expressed. (b) Cells treated for $24 \mathrm{~h}$ with $200 \mathrm{ng} / 5 \times 10^{5} \mathrm{cells} / \mathrm{ml}$ of anti-Fas mAb were resuspended in cell lysis buffer, and $100 \mu \mathrm{g}$ of cellular extract was added to caspase assay buffer with or without $100 \mu \mathrm{M}$ of Boc-D as substrate. After incubation at $37^{\circ} \mathrm{C}$ for $4 \mathrm{~h}$, an absorbance of the yellowish color released by the enzymatic action of caspase 3 was measured using an ELISA reader fitted with a $405 \mathrm{~nm}$ filter. The results shown are the averages of three separate experiments, and the error bars represent s.d.s.

caspase 8 and bid processing by Western blot analysis. Following Fas stimulation, procaspase 8 $(55 / 53 \mathrm{kDa})$ was promptly processed and activated in SKW6.4 cells but not in Hank-1 and NK-YS cells (data not shown). In addition, bid protein was not truncated in Hank-1 or NK-YS cells, whereas the $22 \mathrm{kDa}$-sized wild-type bid expression was markedly attenuated after Fas stimulation in SKW6.4 cells (data not shown). These data demonstrate that in Hank-1 and NK-YS cells, the Fas-mediated signal might be blocked at a proximal step by inhibitors such as c-FLIP before it reaches the mitochondria or executive caspase 3.

\section{Restoration of Sensitivity to Fas-Mediated Apoptosis by CHX in Hank-1 Cells}

Based on reports that the inhibition of Fas-mediated apoptosis by c-FLIP is relieved by protein synthesis inhibitors in various cancer cell lines, ${ }^{11-14}$ we

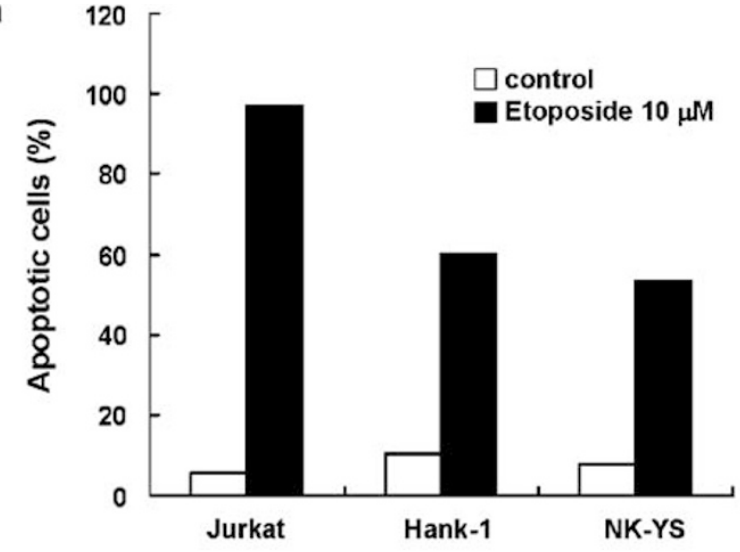

b

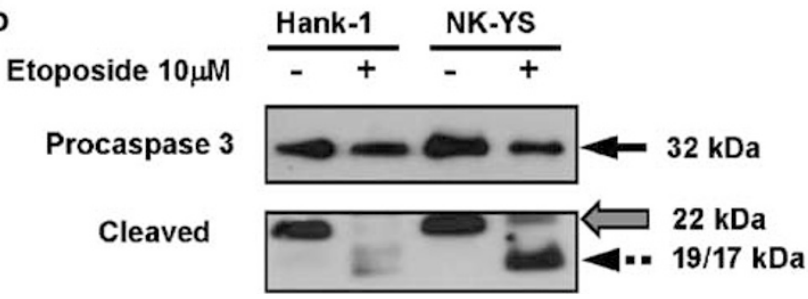

Figure 5 Intact etoposide-induced caspase-3-dependent apoptotic machinery in Hank-1 and NK-YS cells. (a) Hank-1 and NK-YS cells were treated with etoposide at $10 \mu \mathrm{M} / 6 \times 10^{5} \mathrm{cells} / \mathrm{ml}$ and stained with annexin V and PI. Levels of apoptosis were measured by flow cytometry. The data shown represent the total numbers of annexin V- or PI-positive cells. (b) Alterations in caspase 3 levels during etoposide-induced apoptosis were evaluated by Western blotting of cell lysates obtained from the preceding experiment using the two antibodies described in the legend of Figure 3a. Caspase 3 was activated as evidenced by the reduced intensity of procaspase $3(32 \mathrm{kDa})$ (solid arrow) and by the increased intensity of the 19 and $17 \mathrm{kDa}$ blots of active caspase 3 (dash arrow).

investigated the influence of the protein synthesis inhibitor, CHX, on Fas-induced apoptosis in Hank-1 cells. Hank-1 cells were treated with nonlethal doses of CHX ( 5 and $10 \mu \mathrm{M}$ ) with or without anti-Fas mAb for $24 \mathrm{~h}$, and then apoptosis levels were measured by flow cytometry. Interestingly, as shown in Figure 6a, treatment of Hank-1 cells with CHX and anti-Fas $\mathrm{mAb}$ together dramatically increased apoptosis up to $42.4 \pm 20.9$ and $66.2 \pm 9.9 \%$ (mean \pm s.d.) compared with cells treated with anti-Fas mA bonly. The significances of differences were estimated by comparing Fas-induced apoptosis levels between Hank-1 cells treated with and without CHX $(P<0.01)$. In addition, cotreatment of Hank-1 cells with CHX and anti-Fas mAb resulted in an increase in procaspase 8 processing and the mitochondrial membrane potential change (Figure 6b,c). It was likely that CHX enhanced sensitivity to Fasmediated apoptosis by downregulating inhibitory molecules such as c-FLIP. To test this possibility, we examined the effect of CHX on c-FLIP expression level by immunoblotting. As shown in Figure 6d, the level of $\mathrm{C}-\mathrm{FLIP}_{\mathrm{L}}$ was dramatically reduced in CHX-treated Hank-1 cells. However, no marked changes in bcl-2, bcl-xL, or bax expression levels were observed, except for a slight decrease in bax 
a

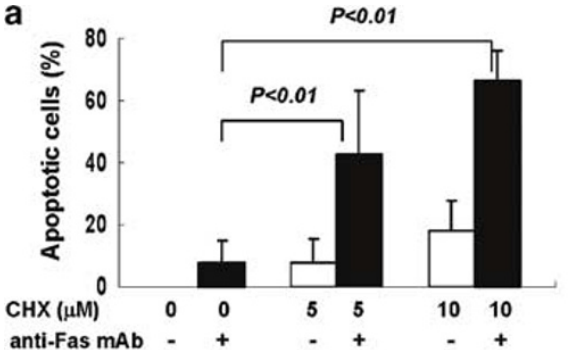

d

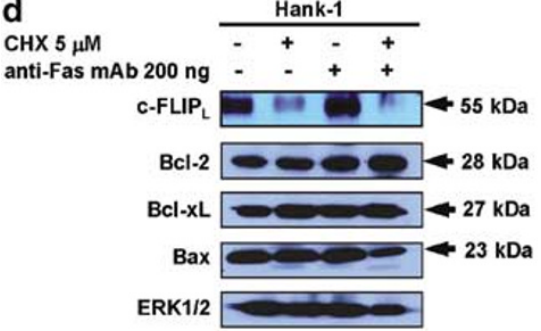

b

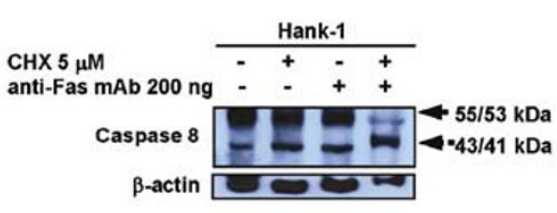

C

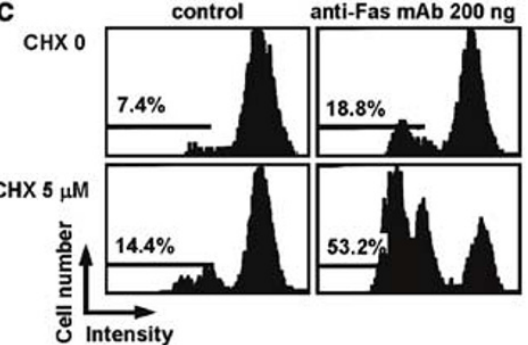

e

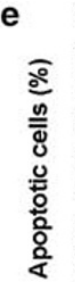

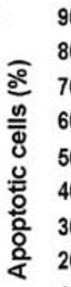

CHX 5

CHX $5 \mu \mathrm{M}-+$

Fas 200ng -

DEX $10 \mu \mathrm{M}$ -

ADR $0.1 \mu \mathrm{M}$ - -

STS $10 \mu \mathrm{M}$ -

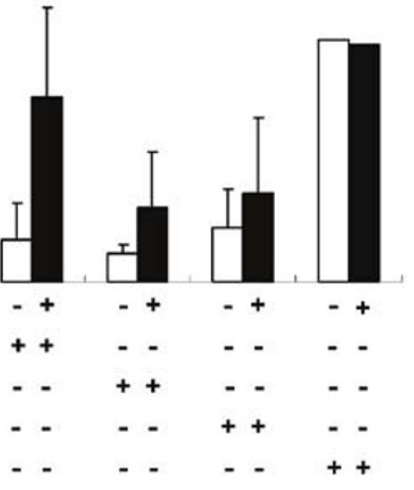

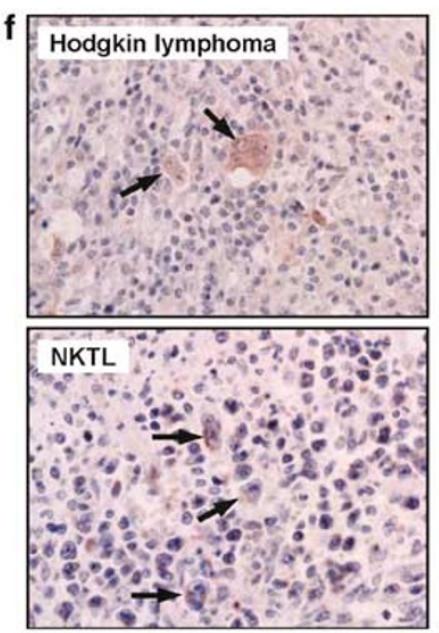

Figure 6 Effect of CHX on Fas-mediated apoptosis in Hank-1 cells. (a) CHX at concentrations of 5 or $10 \mu$ M was applied to Hank-1 cells for $24 \mathrm{~h}$ with or without $200 \mathrm{ng} / 5 \times 10^{5} \mathrm{cells} / \mathrm{ml}$ of anti-Fas mAb. Apoptosis was measured by annexin V and PI staining and flow cytometric analysis. The histogram represents the percentage of apoptotic cells based on the total number of annexin V- or PI-positive cells. The results shown are averages of five separate experiments, and the error bars represent s.d.s. (b) To examine caspase 8 activation after cotreatment with CHX and anti-Fas $\mathrm{mAb}, 30 \mu \mathrm{g}$ of cell lysate from treated cells was subjected to Western blotting using anti-caspase 8 antibody. (c) Mitochondrial membrane potentials were also measured by DiOC 6 staining and flow cytometric analysis in Hank-1 cells treated with CHX and anti-Fas mAb for $24 \mathrm{~h}$, respectively or simultaneously. (d) To evaluate changes in c-FLIP, bcl-2, bcl-xL, and bax expression, Hank-1 cells were treated with CHX $5 \mu \mathrm{M}$ and $/$ or $200 \mathrm{ng} / 5 \times 10^{5} \mathrm{cells} / \mathrm{ml}$ of anti-Fas mAb, and $30-40 \mu \mathrm{g}$ aliquots of cell lysate were subjected to Western blot analysis. (e) To examine the sensitization effect of other apoptotic inducers of CHX in Hank-1 cells, CHX $(5 \mu \mathrm{M})$ was added to Hank-1 cells for $24 \mathrm{~h}$ without or with dexamethasone $(10 \mu \mathrm{M})$, adriamycin $(0.1 \mu \mathrm{M})$, or staurosporin $(10 \mu \mathrm{M})$. Apoptosis was measured by annexin V or PI staining and flow cytometric analysis. The histogram represents the percentage of apoptotic cells defined based on the total number of annexin V- or PI-positive cells. The results shown are averages of two separate experiments, and the error bars represent s.d.s. (f) To examine the in vivo expression of c-FLIP in NKTL, immunohistochemical staining was performed on formalin-fixed paraffin-embedded tissue sections of 36 NKTL patients. c-FLIP was immunostained in the cytoplasm with diffuse or granular pattern (arrows) in Hodgkin/Reed-Sternberg cells of Hodgkin lymphoma (upper panel) and in the tumor cells of NKTLs (lower panel).

level. In addition, CHX did not affect Hank-1 cell death induced by other apoptotic agents not involving the Fas death receptor, that is, by dexamethasone $(10 \mu \mathrm{M})$, adriamycin $(0.1 \mu \mathrm{M})$, or staurosporin $(10 \mu \mathrm{M})$ (Figure 6e). Altogether, these data demonstrate that CHX treatment converts Fas-resistant Hank-1 cells to Fas-sensitive cells probably by desensitizing the effects of inhibitory molecules such as C-FLIP ${ }_{\mathrm{L}}$.

\section{Expression of c-FLIP in NKTL Tissues}

Finally, to elucidate the biological meaning in vivo of the above results obtained from in vitro experiments, we investigated c-FLIP expression in NKTL tissues obtained from 36 patients by immunohistochemistry. c-FLIP immunostaining was observed in the cytoplasm as a diffuse or granular pattern in tumor cells of NKTL and in Hodgkin/Reed-Sternberg cells of Hodgkin lymphoma (Figure 6f). c-FLIP expression was detected in 14 (39\%) of the 36 patients. Therefore, it was considered that resistance to Fas-mediated apoptosis by c-FLIP might contribute to NKTL tumor progression.

\section{Discussion}

NKTL is common in South-East Asia including Korea, Hong Kong, Japan, and China, and in CentralSouth America. NKTL is notable for its clinical aggressiveness and resistance to conventional chemotherapy in the advanced stage. ${ }^{28}$ The observation that apoptotic rates in non-necrotic viable areas are low despite the common immunohistochemical 
expressions of Fas and Fas ligand in NKTL tumor cells, suggests the possibility of Fas resistance in NKTLs. ${ }^{29}$ Frequent Fas gene mutations have been found in studies on NKTL tumor tissues, and these have been suggested to be a major mechanism of resistance to Fas-mediated apoptosis in NKTLs. ${ }^{4,5}$ However, the NKTL cell lines utilized in our study, that is, Hank-1 and NK-YS, exhibited resistance to Fas-mediated apoptosis despite high levels of Fas cell surface expression and the absence of Fas gene mutations. Therefore, we presumed that NKTLs have developed another ways of evading Fasmediated apoptosis.

Fas-mediated apoptosis occurs primarily via two steps, that is, via a proximal signaling pathway after Fas-stimulation and via a subsequent mitochondrial pathway. Cells can be divided into two types according to the main Fas-signaling pathway used. In type I cells, Fas stimulation is followed by large amount of DISC formation and prompt caspase 8 activation, and apoptotic cascades are continued by the direct caspase 3 activation as well as via the mitochondrial pathway. On the other hand, in type II cells, DISC formation is markedly reduced, and caspase activation is preceded by the mitochondrial pathway. ${ }^{1}$ Therefore, although undetectable DISC formation after Fas stimulation may be one of the causes of resistance to Fas-mediated apoptosis, ${ }^{8}$ a reduced level of DISC formation alone is not enough to explain Fas-insensitivity. In Hank-1 and NK-YS cells, participants in the proximal signaling pathway such as Fas, FADD, caspase 8 , and bid protein were all intact, and the nonreceptor-mediated caspase 3-dependent apoptotic machinery provoked by etoposide was also preserved. Nevertheless, Hank-1 and NK-YS cells showed very low rates of Fas-mediated apoptosis. Therefore, we speculated that these cells might resist Fas-mediated apoptosis by blocking efficient proximal signaling.

C-FLIP has two isoforms, c-FLIP long form (c-

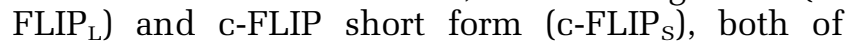
which suppress Fas-mediated apoptosis by interfering with the processing of caspase $8 .^{9}$ In vivo, tumors escape host immune surveillance via the c-FLIP-mediated inhibition of the death receptor pathway, and thus c-FLIP is regarded as a tumor progression factor. ${ }^{30,31}$ High c-FLIP expression has been found in many malignancies, including aggressive B-cell lymphoma, and Hodgkin lymphoma. ${ }^{12,30,32-34}$ In some malignant cells including EBVinfected Burkitt lymphoma, the relative levels of caspase 8 and c-FLIP were reported to determine susceptibility to Fas-mediated apoptosis. ${ }^{10,35}$ Moreover, the downregulation of C-FLIP sensitized Hodgkin lymphoma cells, ${ }^{14}$ hepatocellular carcinoma cells, ${ }^{12}$ Jurkat T-cell lymphoma cells, ${ }^{11}$ osteosarcoma cells, ${ }^{13}$ and endothelial cells ${ }^{36}$ to Fas-mediated apoptosis. c-FLIP is a short-lived protein, and thus the prototypic method used to downregulate c-FLIP is protein synthesis inhibition by CHX. In our study, treatment with sublethal doses of CHX dramatically restored sensitivity to Fas-mediated apoptosis in Hank-1 cells, and this was accompanied by the cleavage of procaspase 8 and an alteration in mitochondrial membrane potential along with the downregulation of c-FLIP $\mathrm{L}_{\mathrm{L}}$ expression. We tried to downregulate c-FLIP expression selectively by treating with c-FLIP antisense oligonucleotides; however, this failed due to the very low transfection efficiency of Hank-1 cells. The in vivo demonstration of c-FLIP expression in 39\% of NKTL patients further suggests that c-FLIPmediated resistance to Fas might enable tumor cells to escape host immune response and play a role in the pathogenesis of NKTL. C-FLIP expression is regulated by $\mathrm{NF}-\kappa \mathrm{B}$ and the PI3K/Akt pathway. ${ }^{37,38}$ In Hodgkin lymphoma, NF- $\kappa$ B modulated c-FLIP-mediated tumor cell resistance to apoptosis induced by death receptor, which was restored by CHX- and by the small interfering RNA (siRNA)-induced downregulation of c-FLIP. ${ }^{14}$ In Hank-1 cells, LMP1 was expressed at high levels as determined by immunoblotting (data not shown). LMP1 induces various antiapoptotic molecules, and promotes cell survival through the activation of NF$\kappa \mathrm{B}$ and PI3K/Akt pathways. ${ }^{21,22}$ Recently, it was reported that c-FLIP is one of the proteins induced by LMP1 in an NF- $\kappa$ B-dependent manner in EBVinfected B lymphoblastoid cell lines. ${ }^{39}$ Therefore, it is conceivable that c-FLIP might be actively upregulated in Hank-1 cells by the constitutive LMP1induced activation of the NF- $\kappa \mathrm{B}$ and PI3K/Akt pathways. This issue must be progressed by obtaining direct evidence.

Unlike c-FLIP, DAP kinase does not actively participate in DISC, but rather functions further downstream of death receptor complex and upstream of other caspases. ${ }^{25}$ Death receptor pathways may convey signals to diverse branches, and DAP kinase functions along some of these branches. ${ }^{25}$ Therefore, the functional significance of DAP kinase during death-receptor mediated apoptosis differs in cell lines, and some DAP kinase-negative cell lines commit to TNF- $\alpha$-induced apoptosis. ${ }^{40}$ Despite the absence of DAP kinase expression due to its promoter methylation, the Fas-mediated apoptosis of Hank-1 cells was restored by CHX treatment. However, the recovery of DAP kinase expression by treating with demethylating agent did not sensitize Hank-1 to Fas-mediated apoptosis. Therefore, we conclude that DAP kinase does not play an important role in Fas-mediated apoptosis in Hank1 cells.

During our apoptotic experiments, the intermediate form of caspase $3(22 \mathrm{kDa})$ was found to be present constitutively in Hank-1 and NK-YS cells. Moreover, when RT-PCR products were sequenced, we did not observe either transcripts of the unexpected size or mutations of caspase 3 transcripts (data not shown). During caspase 3 activation, initial cleavage occurs between the small and large procaspase 3 subunits at a site recognized by initiator 
caspase 8 and 9 , and by granzyme $\mathrm{B}$, which gives rise to a $22 \mathrm{kDa}$ intermediate product. However, this intermediate form of caspase 3 does not have caspase 3 activity in itself, but it must be autocatalytically further processed to $19 / 17 \mathrm{kDa}$-sized active forms. NKTLs have abundant cytotoxic granules containing granzyme B. Granzyme B has been reported to be responsible for the partial processing of caspase 3 in activated nonapoptotic CD3-positive cytotoxic T cells. ${ }^{41}$ The inhibition of granzyme B serine protease activity by Z-ADD.cmk in Hank-1 and NK-YS cells diminished the intermediate form of caspase 3 without affecting cell viability (data not shown). Inhibitors of apoptosis (IAP) family proteins and the small heat shock protein $\alpha \mathrm{B}$-crystallin have been known to block the autocatalytic processing of intermediate caspase $3 ;^{42,43}$ however, the physiologic roles of this partial processed caspase 3 remain unknown.

In conclusion, this study revealed that CHX treatment causes the Fas-resistant NKTL cell line, Hank-1, to become Fas-sensitive, probably by relieving c-FLIP ${ }_{\mathrm{L}}$-mediated inhibition of the proximal Fas signaling pathway. Moreover, some NKTL tissues were found to express c-FLIP in tumor cells. Our results suggest that c-FLIP-mediated Fas-induced apoptosis inhibition is a mechanism that underlies the development and progression of NKTL. Thus, the modulation of the Fas-mediated apoptotic pathway by CHX should be viewed as a potential therapeutic target in NKTL.

\section{Acknowledgements}

This work was supported by the Korea Science \& Engineering Foundation (KOSEF) through the Tumor Immunity Medical Research Center at Seoul National University College of Medicine.

\section{References}

1 Scaffidi C, Fulda S, Srinivasan A, et al. Two CD95 (Apo-1/Fas) signaling pathways. EMBO J 1998;7: 1675-1687.

2 Thornberry NA, Lazebnik Y. Caspases: enemies within. Science 1998;281:312-316.

3 French LE, Tschopp J. Defective death receptor signaling as a cause of tumor immune escape. Semin Cancer Biol 2002;12:51-55.

4 Shen L, Liang ACT, Lu L, et al. Frequent deletion of Fas gene sequence encoding death and transmembrane domains in nasal natural killer/T cell lymphoma. Am J Pathol 2002;161:2123-2131.

5 Takakuwa T, Dong Z, Nakatsuka S, et al. Frequent mutations of Fas gene in nasal NK/T cell lymphoma. Oncogene 2002;21:4702-4705.

6 Siegel RM, Frederiksen JK, Zacharias DA, et al. Fas preassociation required for apoptosis signaling and dominant inhibition by pathogenic mutations. Science 2000;288:2354-2357.
7 Cheng J, Zhou T, Liu C, et al. Protection from Fasmediated apoptosis by a soluble form of the Fas molecule. Science 1994;263:1759-1762.

8 Snow AL, Chen LJ, Nepomuceno RR, et al. Resistance to Fas-mediated apoptosis in EBV-infected B cell lymphoma is due to defects in the proximal Fas signaling pathway. J Immunol 2001;167:5404-5411.

9 Irmler M, Thome M, Hahne M, et al. Inhibition of death receptor signals by cellular FLIP. Nature 1997;388: 190-195.

10 Krueger A, Baumann S, Krammer PH, et al. FLICEinhibitory proteins: regulators of death receptormediated apoptosis. Mol Cell Biol 2001;21:8247-8254.

11 Tran SEF, Meinander A, Holmstrõm TH, et al. Heat stress downregulated FLIP and sensitizes cells to Fas receptor-mediated apoptosis. Cell Death Differ 2003; 10:1137-1147.

12 Okano H, Shiraki K, Inoue $\mathrm{H}$, et al. Cellular FLICE/ caspase-8-inhibitory protein as a principal regulator of cell death and survival in human hepatocellular carcinoma. Lab Invest 2003;83:1033-1043.

13 Kinoshita H, Yoshikawa H, Shiki K, et al. Cisplatin (CDDP) sensitizes human osteosarcoma cell to Fas/ CD95-mediated apoptosis by down-regulating FLIP-L expression. Int J Cancer 2000;88:986-991.

14 Mathas SM, Lietz A, Anagnostopoulos I, et al. c-FLIP mediates resistance of Hodgkin/Reed-Sternberg cells to death receptor-induced apoptosis. J Exp Med 2004; 199:1041-1052.

15 Liang R, Todd D, Chan TK, et al. Treatment outcome and prognostic factors for primary nasal lymphoma. J Clin Oncol 1995;13:666-670.

16 Cheung MM, Chan JK, Lau WH, et al. Primary nonHodgkin's lymphoma of the nose and nasopharynx: clinical features, tumor immunophenotype, and treatment outcome in 113 patients. J Clin Oncol 1998;16: $70-77$.

17 Hammerschimidt W, Sugden B. Genetic analysis of immortalizing functions of Epstein-Barr virus in human B lymphocytes. Nature 1989;340:393-397.

18 Wang D, Liebowitz D, Kieff E. An EBV membrane protein expressed in immortalized lymphocytes transforms established rodent cells. Cell 1985;43:831-840.

19 Izumi KM, Kieff ED. The Epstein-Barr virus oncogene product latent membrane protein 1 engages the tumor necrosis factor receptor-associated death domain protein to mediate B lymphocyte growth transformation and activate NF- $\kappa$ B. Proc Natl Acad Sci USA 1997; 94:1447-1452.

20 Roberts ML, Cooper NR. Activation of a ras-MAPKdependent pathway by Epstein-Barr virus latent membrane protein 1 is essential for cellular transformation. Virology 1998;240:93-99.

21 Huen DS, Henderson SA, Croom-Carter D, et al. The Epstein-Barr virus latent membrane protein-1 (LMP1) mediates activation of NF-kappa B and cell surface phenotype via two effector regions in its carboxyterminal cytoplasmic domain. Oncogene 1995;10: 549-560.

22 Dawson CW, Tramountanis G, Eliopoulos AG, et al. Epstein-Barr virus latent membrane protein 1 (LMP1) activates the phosphatidylinositol 3-kinase/Akt pathway to promote cell survival and induce actin filament remodeling. J Biol Chem 2003;278:3694-3704.

23 Kagami Y, Nakamura S, Suzuki R, et al. Establishment of an IL-2-dependent cell line derived from 'nasaltype' NK/T-cell lymphoma of CD2+, sCD3-, CD3 $\varepsilon+$, 
CD56+ phenotype and associated with the EpsteinBarr virus. Br J Haematol 1998;103:669-677.

24 Tsuchiyama J, Yoshino T, Mori M, et al. Characterization of a novel human natural killer-cell line (NK-YS) established from natural killer cell lymphoma/leukemia associated with Epstein-Barr virus infection. Blood 1998;92:1374-1383.

25 Cohen O, Inbal B, Kissil JL, et al. DAP-kinase participated in TNF- $\alpha$ - and Fas-induced apoptosis and its function requires the death domain. J Cell Biol 1999;146:141-148.

26 Nakatsuka S, Takakuwa T, Tomita Y, et al. Hypermethylation of death-associated protein (DAP) kinase CpG island is frequent not only in B-cell but also in $\mathrm{T}$ - and natural killer (NK)/T-cell malignancies. Cancer Sci 2003;94:87-91.

27 Martin SJ, Green DR. Protease activation during apoptosis: death by thousand cuts? Cell 1995;82: 349-352.

28 Ko YH, Kim CW, Park CS, et al. REAL classification of malignant lymphomas in the Republic of Korea: incidence of recently recognized entities and changes in clinicopathologic features. Hematolymphoreticular Study Group of the Korean Society of Pathologists. Cancer 1998;83:806-812.

$29 \mathrm{Ng}$ CS, Lo ST, Chan JK. Peripheral T and putative natural killer cell lymphomas commonly coexpress CD95 and CD95 ligand. Hum Pathol 1999;30:48-53.

30 Medema JP, de Jong J, van Hall T, et al. Immune escape of tumors in vivo by expression of cellular FLICEinhibitory protein. J Exp Med 1999;190:1033-1038.

31 Djerbi M, Screpanti V, Catrina AI, et al. The inhibitor of death receptor signaling, FLICE-inhibitory protein defines a new class of tumor progression factors. J Exp Med 1999;190:1025-1032.

32 Ryu BK, Lee MG, Chi SG, et al. Increased expression of cFLIP(L) in colonic adenocarcinoma. J Pathol 2001; 194:15-19.

33 Bullani RR, Huard B, Viard-Leveugle I, et al. Selective expression of FLIP in malignant melanocytic skin lesions. J Invest Dermatol 2001;117:360-364.
34 Thomas RK, Kallenborn A, Wickenhauser C, et al. Constitutive expression of c-FLIP in Hodgkin and Reed-Sternberg cells. Am J Pathol 2002;160:15211528.

35 Tepper CG, Seldin MF. Modulation of caspase-8 and FLICE-inhibitory protein expression as a potential mechanism of Epstein-Barr virus tumorigenesis in Burkitt's lymphoma. Blood 1999;94:1727-1737.

36 Suhara T, Mano T, Oliveria BE, et al. Phosphatidylinositol 3-Kinase/Akt signaling controls endothelial cell sensitivity to Fas-mediated apoptosis via regulation of FLICE-inhibitory protein. Circ Res 2001;89: 13-19.

37 Barkett M, Gilmore TD. Control of apoptosis by Rel/ NF-kappaB transcription factors. Oncogene 1999;18: 6910-6924.

38 Panka DJ, Mano T, Suhara T, et al. Phosphatidylinositol 3-kinase/Akt actively regulates c-FLIP expression in tumor cells. J Biol Chem 2001;276:6893-6896.

39 Cahir-McFarland ED, Carter K, Rosenwald A, et al. Role of NF- $\kappa \mathrm{B}$ in cell survival and transcription of latent membrane protein 1-expressing or Epstein-Barr virus latency III-infected cells. J Virol 2004;78:41084119.

40 Inbal B, Cohen O, Polak-Charcon S, et al. DAP kinase links the control of apoptosis to metastasis. Nature 1997;390:180-184.

41 Bidère $\mathrm{N}$, Briet $\mathrm{M}$, Dürrbach $\mathrm{A}$, et al. Selective inhibition of dipeptidyl peptidase I, not caspases, prevents the partial processing of procaspase-3 in CD3activated human CD8+ T lymphocytes. J Biol Chem 2002;277:32339-32347.

42 Deveraux QL, Roy N, Stennicke HR, et al. IAPs block apoptotic events induced by caspase-8 and cytochrome $c$ by direct inhibition of distinct caspases. EMBO J 1998;17:2215-2223.

43 Kamradt MC, Chen F, Cryns V. The small heat shock protein (B-Crystallin) negatively regulates cytochrome $C$ - and caspase-8-dependent activation of caspase-3 by inhibiting its autoproteolytic maturation. J Biol Chem 2001;276:16059-16063. 